\title{
What Bavarian Negative Concord Reveals about the Syntactic Structure of German*
}

\author{
Josef Bayer \\ Max-Planck-Institute for Psycholinguistics, Nijmegen
}

\section{INTRODUCTION}

Since the dawn of generative linguistics, there has been an ongoing debate about the question whether German has a truly configurational syntactic structure like English, French, and Italian or whether it is more on the side of socalled 'non-configurational' or 'free word order' languages like Hungarian or Latin. More recently, a consensus seems to have been reached in favor of at least a weakly configurational structure, whatever this may be when observation comes down to a theoretical implementation. The question at present is not so much whether German makes use of a maximal V-projection which does not include the subject-NP, but rather how one can account for the 'scrambling' phenomena which make German markedly different from English or even from such a closely related language as Dutch. In this contribution, I will consider some hitherto undiscussed data which turn out to be relevant both for the configurationality debate and for the German scrambling facts. The present data come from Bavarian, a non-standard variety of German, which is spoken in Bavaria and parts of Austria. Like many other languages of the world, including substandard English, Bavarian shows the negative concord phenomena, i.e. there may be more than one carrier for the negative element in a single sentence while its semantics is that of simplex negation. This phenomenon is well studied in languages in which negative concord (NC) or double negation belongs to the standard language, as in Italian (see Rizzi, 1982). It is less often studied in languages, however, where it is considered substandard. An exception is Labov (1972) which contains a detailed analysis of NC in Black American English. In section 1, a subject/object asymmetry will be discussed which arises in Bavarian sentences with NC. In section 2, an account for NC will be proposed which will then serve as a basis for the evaluation of the scrambling phenomena toe be introduced in section 3 . 
1. A SUBJECT/OBJECT ASYMMETRY

In Italian one usually finds $\mathrm{NC}$ only in those cases in which a negative quantifier such as nessuno ('nobody') or niente ('nothing') appears inside the VP. Rizzi (1982) discusses cases such as the following:

(1) a. Mario *(non) ha visto nessuno Mario not has seen nobody 'Mario hasn't seen anybody

b. Nessuno (*non) ha visto Mario 'Nobody has seen Mario'

(2) Non pretendo che nessuno sia arrestato not (I) demand that nobody be arrested 'I don't demand that nobody should be arrested'

b. Non pretendo che sia arrestato nessuno

'I don't demand that anybody should be arrested'

Provided that the semantics represents the reading given in the glosses, (1a) is illicit when non is absent, while (1b) is illicit when non is present. (2) shows that what matters is not just the status of the negative quantifier as subject or object, but rather its position in the clause: In (2a), the negation nessuno cannot be 'absorbed' by the negation in the matrix clause, but when subject inversion has applied as in (2b), it can. Rizzi, following Kayne (1981), explains these cases with an application of the Empty Category Principle (ECP) (see Chomsky, 1981) at the level of Logical Form (LF): when the negation inherent in the quantifier is associated with the negative element non, an ECP-violation will arise in those cases where the negative quantifier is not properly governed. Since nessuno in (1a) is governed by the verb, no ECP-violation will arise. In (2a) the negation inherent in nessuno cannot be associated with non, because it is not in a properly governed position. When nessuno appears in the government domain of the verb, however, the association is licit, as shown in (2b). Rizzi gives independent evidence from the syntax of movement which corroborates his analysis.

In order to account for (1b) one has to say that non must c-command the negative quantifier in order to make the association possible. It is this case which we also find in most varieties of Black English and in Bavarian. According to Labov, Black English as well as the majority of white dialects with NC require a negated auxiliary to c-command the negative quantifier. The following examples are drawn from Labov (1972):
(3) a. I don't measure nothing

b. You don't have to know too much of nothing

c. He didn't take nothin' offa nobody

d. I ain't never had no trouble with none of 'em

For many speakers, NC with the preverbal position is considered to be ungram matical. But Labov also found a group of speakers who produce sentences such as:

(4) a. Nobody don't like a boss hardly

b. Down here nobody don't know about no club

c. None of our friends don't fight 'im

d. None of 'em can't fight

Similar facts are reported from first language acquisition in Bellugi (1971).

In Bavarian, NC from inside VP is always possible and for certain speakers it is the rule, while NC from the VP-external position is perceived as ungrammatical. The data in (5) are drawn from Ludwig Thoma's satirical works 'Briefwexel eines bayrischen landtagsabgeordneten' (1909) and 'Jozef Filsers Briefwexel' (1912): ${ }^{1}$

(5) a. ich bin froh, das ich keine Rede nicht halden brauch,... I am glad that I no talk not give need 'I am glad that I don't have to give a talk'

b. Also brauchst keine Angst nicht haben thus need(2sg) no fear not have 'Thus, you don't need to worry'

c. sondern ich geh auf keine Rehdutt nicht mehr but I go to no carnevall-ball not more 'But I will never go to a carneval-ball again'

d. und keinen andem nichd leihden wiel and no other not tolerate wants 'and does not want to tolerate another one'

In theses examples the negative quantifier is undoubtedly in the VP in which nicht occurs. However, the sentences in (6) are generally rejected by speakers of NC-dialects unless true double negation in the logical sense is intended.

(6) a. *das koa Mensch des Zeich ned ooschaung woidd that no man this stuff not look-at wanted 'that no one wanted to look at this stuff' 
b. *das koana in des Audo ned eig'schdieng is that no one in that car not entered is 'that no one got in this car'

c. *das neamads da Soffi ned wehdua woidd that no one the Sophie not hurt wanted 'that no one wanted to hurt Sophie'

In these examples, the negative quantifier NP remains outside the VP, given a configurational structure of German. Things are, however, not always that straightforward. There exist cases in which NC with the subject-NP does occur. Here are some more of Thoma's examples:
a. das keine Unanstendikeit nichd bassirt isd that no indecency not happened is 'that no indecency has occurred'
b. und keine Todsiende nichd forfiel and no mortal sin not occurred 'and no mortal sin occurred'
c. hobwohl jez in der kuhltur keine arbeid nicht zum ferrichten ist although now in the culture no work not to do is 'although there is at present no cultural work to do'
d. intem das keine keischheid nichd dabei sein mus in that no chastity not involved be must 'since chastity does not have to be involved'

In (7a) and (7b) the verbs passieren en vorfallen are ergative verbs in the sense of Burzio (1986). Let us assume that their nominative argument must arise inside VP for principled reasons. Keine arbeid in (7c) is the underlying object of the verb verrichten, which appears in a quasi passive-construction (see Haider, 1984). There are reasons to attribute VP-internal status to such NPs (see Fanselow, 1987, ch.3). (7d) involves the copula sein; it can be analyzed as an expletive construction (see Safir, 1985, who argues for an empty expletive element in subject position).

Jarich Hoekstra (p.c.) informs me that Frisian, another NC-language, exhibits a very similar subject/object asymmetry. Since Frisian has an overt expletive element (der), one can test whether, when it is present, NC with the subject is possible; and indeed, NC with the subject is permitted only in this case i.e. when the negative subject-NP arguably occurs inside the VP.

Provided that this is so, we have found a subject/object asymmetry which can be captured with the following generalization:

(8) NC in Bavarian can only hold between a (primary) negative element $\mathrm{X}$ and a negative quantified constituent $\mathrm{Y}$ if both $\mathrm{X}$ and $\mathrm{Y}$ are VP-internal. 
In the next section we will discuss some of the consequences of this generalization for the syntax of Bavarian, and, by extension, for the syntax of German.

\section{TWO RULES OF NEGATIVE CONCORD}

As in Italian and in most varieties of substandard English with NC, Bavarian requires a command-relation between the negative element nicht (or ned) and the negative quantifier. We will assume that nicht is a syncategorematic expression (somewhat like a focussing particle, see Jacobs, 1982; 1983), which in the unmarked case adjoins to $V^{\circ}{ }^{2}$ The element NEG and $V$ together form an new V. It appears that a negative quantifier must be c-command by this negative verb. C-command is to be understood in the strict sense of Reinhart (1976).

(9) $\quad \alpha$ c-commands $\beta$ iff the first branching node dominating $\alpha$ also dominates $\beta$ and neither $\alpha$ dominates $\beta$ nor $\beta$ dominates $\alpha$.

As shown in the example in (5), the negated $\mathrm{V}$ always c-commands the XP containing kein. (5c) shows that what counts is the verb's D-structure position. Given that what we have said about the examples in (7) is tenable, the nominative-NP is also in the VP and will be c-commanded by the negated V. ${ }^{3}$ In (6), however, this is crucially not the case. The adoption of the definition in (9) correctly predicts that the following constructed examples are ungrammatical as well:

a. *das da Bene koan Mensch im Haus ned g'seng hod that the Bene no man in the house not seen has that Bene hasn't seen anyone in the house'

b. *das da Bene koamoanzign d'Soffi ned vorg'schdööd hod that the Bene no single (dat.) the Sophie not introduced has 'that Bene hasn't introduced Sophie to a single person'

We assume the following LF-rule for NC: 
(11) NC-Rule $(I)^{4}$

$$
\begin{aligned}
& \text { SS: }\left[_{\alpha} \ldots\left[\left[_{\mathrm{XP}} \mathrm{NEG} \ldots\right]_{\mathrm{j}} \ldots \mathrm{NEG}+\mathrm{V}\right] \rightarrow\right. \\
& \text { LF: }\left[\left[_{\alpha} \ldots[\mathrm{XP} \ldots]_{\mathrm{j}} \ldots \mathrm{NEG}_{\mathrm{j}}+\mathrm{V}\right]\right.
\end{aligned}
$$

where $\alpha$ is a domain $Y$ in which NEG $+\mathrm{V}$ c-commands XP.

In all cases to be discussed here, XP will be reprented at LF as an existentially quantified NP..$^{5}$ At LF, NEG raises to VP. Since XP is coindexed with NEG and since it is a quantified phrase (QP), it will also raise to VP. This gives the intermediate structure in (12):

(12) $\left[\mathrm{VP}_{\mathrm{VP}} \mathrm{NEG} \mathrm{QP}_{\mathrm{i}}\left[\mathrm{VP} \ldots\left[\mathrm{XP}_{\mathrm{XP}} \mathrm{e}_{\mathrm{i}}\right] \ldots \mathrm{V}\right]\right]$

From this position NEG + QP can raise to IP, which corresponds to the previously used sentence ' $S$ ' (see Chomsky, 1986).

The question is whether there is empirical motivation for this particular proposal. We think there is. Recall that we have found an asymmetry with respect to the position of the QP in an NC construction. Consider now the following examples by Thoma:

(13) a. $\mathrm{Zu}$ der weldlichen Obrikeid had kein Mentsch kein Ferdrauen to the mundane authority has no man no trust

'No one trusts mundane authority'

b. Gozeidank had keine Zeitung nichz erfarren

Thank God has no paper nothing experienced

'Thank God, no newspaper has caught wind of anything'

In these examples there is no NEG-element nicht, but two negative QPs. NC applies here as well, but it is always possible for the subject-NP to absorb the negation of the object-NP. We have seen before that $\mathrm{NC}$ is not licensed when NEG does not c-command the negative QP. In this case, however, the lower QP will never c-command the subject-QP. We therefore adopt a second NCrule. This may be seen as a subcase of the rule of Quantifier Raising (QR):

(14) NC-Rule (II)

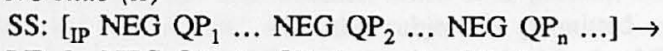

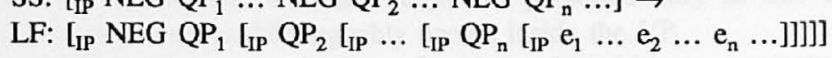

(14) says that any NEG $\mathrm{QP}_{\mathrm{k}}$ (with $\mathrm{k}>1$ ) will transmit its $\mathrm{NEG}$ element to $\mathrm{QP}_{1}$ when $\mathrm{QR}$ applies. This derives the NC-reading of the examples in (13).

Coming back to (12), rule (14) predicts that negative QPs whose negation was previously absorbed according to rule (11) will also be affected. If (14) would raise a negative QP before (11) has applied, readings would emerge which do not conform to NC. Cases such as (15), however, get a natural NC-reading:

(15) das koa Mensch [de Jager koa Bier ned zoid hod] that no man the hunter no beer not paid has 'that no one paid the hunter a beer'

Once (11) has applied to the VP, (15) will be as in (12), i.e. the negation inherent in koa Bier is absorbed by ned and both NEG and the QP (corresponding to "a beer") are adjoined to VP. Rule (14) will affect this newly formed negative QP and raise it to IP where its inherent negation is absorbed by the negation inherent in the subject-NP koa Mensch. The LF of (15) is:

(16) NEG QP [IP $_{\text {QP }}$ [IP $_{1} e_{1}$ VP $_{2} e_{2}$ [VP de Jager $e_{2}$ zoid hod] $\left.\left.]\right]\right]$

This seems to be a proper basis for interpreting (15) in Bavarian. In the next section we will return to rule (11) and see what it predicts for subject/object scrambling and object-cliticization to COMP.

\section{NEGATIVE CONCORD AND SCRAMBLING}

Consider the following sentences of Standard German (both of which have an equivalent in Bavarian):
a. daß den Postboten
der Hund
gebissen hat that the postman (acc) the dog(nom) bitten has 'that the dog has bitten the postman'
b. daß ihn der Hund gebissen hat 'that the dog has bitten him'

Consider furthermore that both of these examples are represented at S-structure with a trace to the immediate left of gebissen. This trace would be bound by the object-NP in (17a) and by the object-clitic in (17b):

(18) $\left[{ }_{\mathrm{IP}}[\mathrm{NP} / \mathrm{CLITIC}]_{\mathrm{i}}\left[_{\mathrm{IP}} \mathrm{NP}_{\mathrm{NOM}}\left[\mathrm{VP}_{\mathrm{VP}} \mathrm{e}_{\mathrm{i}} \mathrm{V} \ldots\right]\right]\right.$

In the previous sections we have seen that $\mathrm{NC}$ between nicht (ned) and a negative QP is only permitted when the negated V c-commands QP. In (18), V crucially does not c-command the $\mathrm{NP}_{\mathrm{NOM}}$. If $\mathrm{V}$ is an agentive verb like beissen, we can exclude the possibility that its subject-NP is an underlying object. With this prerequisite, (18) should disallow a NC-reading when $\mathrm{NP}_{\mathrm{NOM}}$ is a negative 
QP and V is negated. This prediction is wrong, as shown by the following pairs of examples:
(19)
*das koa Hund
an Bosdboon
ned beisd
that no $\operatorname{dog}(\mathrm{nom})$ the postman (acc) not bites
b. das an bosdboon koa Hund ned beisd
* das koa Hund
eam
ned beisd
that no $\operatorname{dog}($ nom) him $(\mathrm{acc})$ not bites

b. das'n koa Hund ned beisd

While the canonical a-sentences are sharply ungrammatical (under an NC reading), the scrambled $b$-sentences are perfect. I conclude from this that (18) cannot be the right representation for scrambling or clitic movement in German. In order to acknowledge the fact that nicht (ned) has to c-command the $\mathrm{QP}$ whose negation it will absorb, the negated $\mathrm{V}$ will have to c-command the subject-NP. This could be achieved when we allow sentences like those in (17) as well as (19b) and (20b) to be base-generated. The question is not so much whether this can be done, but whether there are independent reasons to do so. I believe a major reason for advocating a base-generation account is that I(NFL) is not a syntactic category in German, but a morphological element that projects 'in tandem' with the verb. In this sense, an inflected verb is both V and I at the same time. Let us assume that the elementary projection of an inflected $\mathrm{V}$ looks as follows:

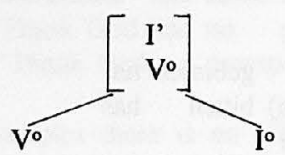

In (21), I is the formal head of $V^{\circ}$. Attachment to $V^{\circ}$, which is stem, results in I'. Only at the mother node in (21) is the word-level reached. This mother node is the minimal element that counts as a syntactic category in German. What is special about this node is that it combines two functors, a lexical functor an a functional one. In the same way as V seeks an NP to its left to which it will assign an object Case and a theta-role, I' will seek a specifier-NP to which it can (via $\mathrm{I}^{\circ}$ ) assign nominative Case. If this natural assumption is made, (21) is allowed to project as follows:
(22)

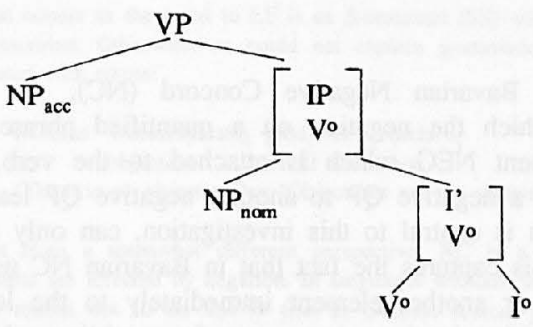

Lack of space prevents me from going into this any further. It should, however, be clear that such a system allows for at least a descriptive account of scrambling and clitic movement, without making reference to 'movement' in the nonmetaphorical sense.

This sketch should suffice to show how the Bavarian NC-facts in (19) and (20) can be derived: since only the mother node in (21) is a syntactic word NEG will adjoin to this node and never to anything dominated by it. In the following structure of $(19 \mathrm{~b})$ the negated $\left[\mathrm{I}^{\prime}, \mathrm{V}\right]$-category $\mathrm{c}$-commands the Q-NP koa Hund, and the predictions of the NC-rule in (11) go through.

(23)

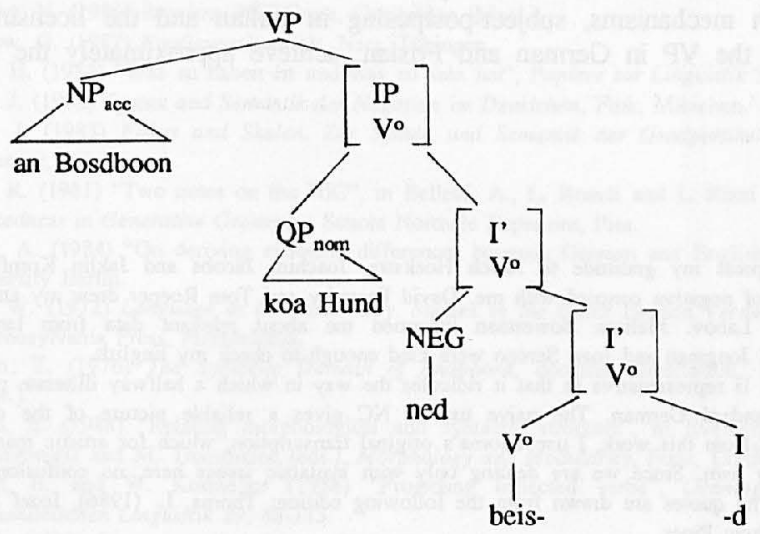

It is interesting to see that "movement" of an object-clitic across a negative subject-QP makes the use of NC also possible in Frisian (Jarich Hoekstra, p.c.). 


\section{CONCLUSION}

In this brief investigation of Bavarian Negative Concord (NC), we have proposed two rules, one by which the negation on a quantified phrase gets absorbed by the negative element NEG which is attached to the verb, and another by which the raising of a negative QP to another negative QP leads to absorption. The first rule, which is central to this investigation, can only apply when NEG c-commands QP. This captures the fact that in Bavarian NC usually applies when $\mathrm{Op}$ is an object or another element immediately to the left of $\mathrm{NEG}+\mathrm{V}$. Then we have shown that in those instances of scrambling where a negative subject-QP appears immediately to the left of NEG+V, NC is fully operative. This is a strong reason against scrambling as an instance of the rule Move-Alpha. If at S-structure NEG+V would c-command an object-trace, the NC-rule could not apply. Since the NC-rule does apply, we have concluded that the subject-NP can be base-generated to the immediate left of V. This conclusion is supported by the fact that I(NFL) in German is a morphological affix which projects together with the verb.

This finding ties in with Rizzi's (1982) account of negation in Italian as well as with the facts of Frisian which were mentioned in the text. While we have not tried to reduce the Bavarian NC-phenomenon to the ECP, ${ }^{6}$ it should be clear that both mechanisms, subject-postposing in Italian and the licensing of the subject in the VP in German and Frisian, achieve approximately the same goal.

NOTES

I want to express my gratitude to Jarich Hoekstra, Joachim Jacobs and Jaklin Komfilt for discussing issues of negative concord with me. David Pesetsky and Tom Roeper drew my attention to the work of Labov. Melissa Bowerman informed me about relevant data from language acquisition. Allard Jongman and Joan Sereno were kind enough to check my English.

1. Thoma's work is representative in that it ridicules the way in which a halfway illiterate peasant ries to write Standard German. The naive use of NC gives a reliable picture of the dialect. Whenever I quote from this work, I use Thoma's original transcription, which for artistic reasons is different from my own. Sisce we are dealing only with syntactic issues here, no confusions will arise from this. The quotes are Briefwexel. München: Piper.

2. An exception is that it must adjoin to $[\mathrm{PP}+\mathrm{V}]$ when the $\mathrm{PP}$ is subcategorized by $\mathrm{V}$. I have nothing to say about this peculiarity.

3. In the spirit of Kratzer (1984), Reuland and Kosmeijer (1988) and Reuland (1988) we take INFL) as a morphological feature on the verb, i.e. it is crucially not a terminal syntactic node which takes a VP-complement. Rather, I projects together with the verb as a complex category. As such, it can license nominative Case inside the VP. This explains why the subject-NP does not have to move to pre-VP position in order to receive nominative Case. We will retum to this issue in more detail in section 3.
4. What counts as the input to LF is an S-structure (SS) with traces into which moved constituents can reconstruct. Otherwise we could not explain grammatical NCexamples such as (i), which is represented with traces:

(i) [Keinen Wiederspruch $]_{i}$ gibd $_{j}$ es $e_{i}$ nicht $e_{j}$

no objection exists there not

'There is no objection' or 'Objections are not allowed'

5. Seen from a somewhat different perspective, NC is a means to signal at S-structure which constituents are affected by negation. In languages without NC, this relation has to be inferred.

6. One reason not to do this as important a role as it does in oher languages. For example, Wh-island violations are equally ungrammatical when a subject-WH-element or an object-WH-element is extracted. See Bayer (1989).

REFERENCES

Bayer, J. (1989) "Notes on the ECP in English and German", ms. Max-Planck-Institute for Psycholinguistics, Nijmegen.

Bellugi, U. 1971) "Simplification in children's language", in Huxley, R. and E. Ingram (eds.), Language Acquisition: Models and Methods, Academic Press, London.

Burzio, L. (1986) Italian Syntax. A Government-Binding Approach, Reidel, Dordrech.

Chomsky, N. (1981) Lectures on Government and Binding, Foris, Dordrecht.

Chomsky, N. (1986) Barriers, MTT Press, Cambridge (Mass.)

Fanselow, G. (1987) Konfigurationalität, Narr, Tübingen.

Haider, H. (1984) "Was zu haben ist und was zu sein hat", Papiere zur Linguistik 30, 23-35.

Jacobs, J. (1982) Syntax and Semantik der Negation im Deulschen, Fink, München.

acobs, J. (1983) Fokus and Skaten. Zur Syntax und Semantik der Gradpartikein in Deutschen, Niemeyer, Tübingen.

Kayne, R. (1981) "Two notes on the NC", in Belletti, A., L. Brandi and L. Rizzi (eds.), Theory of Markedness in Generative Grammar, Scuola Normale Superiore, Pisa.

Kratzer, A. (1984) "On deriving syntactic differences between German and English", ms. Technical University Berlin.

Labov, W. (1972) Language in the Inner City. Studies in the Black English Vernacular, University of Pennsylvania Press, Philadelphia.

Reinhart, T. (1976) The Syntactic Domain of Anaphora, doctoral dissertation, MIT, Cambridge (Mass.).

Reuland, E. (1988) "Relating morphological and syntactic structure", in Everaert, M., A. Evers, R. Huybregts and M. Trommelen (eds.), Morphology and Modularity, Foris, Dordrecht.

Reuland, E. and W. Kosmeijer (1988) "Projecting inflected verbs", Groninger Arbeiten zur Germanistischen Linguistik 29, 88-113.

Rizzi, L. (1982) Issues in Italian Syntax, Foris, Dordrecht.

Safir, K. (1985) Syntactic Chains, Cambridge University Press, Cambridge. 